\title{
Transference and countertransference in communication between doctor and patient
}

\author{
Patricia Hughes \& Ian Kerr
}

\begin{abstract}
"The reasonable man adapts himself to the world; the unreasonable one persists in trying to adapt the world to himself" George Bernard Shaw, Maxims for Revolutionists.
\end{abstract}

Health care is a complex business. Medical treatment could be so much more reliable if it were not compromised by the imprecise and unpredictable nature of human motivation. But even the best treatment will not always be good enough, and patients who hoped for a cure will be disappointed, afraid and angry. Some patients have confusing expectations. Although rationally we know that being ill or having poor relationships or not being able to work is unpleasant, some people have mixed feelings about losing their symptoms. Patients are not always grateful for our honest attempts to help them, and a few emerge almost triumphant from a long treatment with symptoms intact. Doctors cannot escape the burden of their own motivation. Most of us believe that the ability to feel for our patients is an important dimension of treatment. This comes at a price: we have our own needs and desires, and the therapeutic relationship is a fertile ground where these may be played out.

\section{The therapeutic alliance}

A cornerstone of treatment in medicine is the therapeutic alliance, whereby patient and doctor establish a rational agreement or contract which supports the treatment (Greenson, 1985). So the patient with a sore throat has the rational expectation that the doctor is appropriately qualified, will do a suitable examination and investigation, and will prescribe relevant treatment. The doctor expects that the patient who has sought treatment will generally do his or her best to comply with the treatment requirements such as collecting a prescription and taking the prescribed medication.

The therapeutic alliance in this transaction has a good chance of survival: the negotiation is straightforward and there is unlikely to be a covert agenda. However, as the patient's needs become more complex, the therapeutic alliance may be distorted by the wishes and expectations of the patient and even occasionally the doctor. These may be fully conscious and explicit, or may not be entirely conscious and so be communicated in a non-direct way (Balint, 1957) (see Box 1).

\section{The covert agenda}

We need and want a variety of relationships throughout our life. Although this primary need is biologically determined by genes that promote survival of the species, the precise nature of the relationships we seek is heavily influenced by our previous experience. For example, attachment research has conclusively demonstrated the effect of a parent's attitude to attachment on the infant's subsequent behaviour with him or her (Fonagy et al,

Patricia Hughes is a senior lecturer and consultant in psychotherapy at St George's Hospital Medical School and South West London and St George's Mental Health Trust (St George's Hospital Medical School, London SW17 0RE, Tel: 0181 725 5521/31; e-mail: p.hughes@sghms.ac.uk). She is interested in teaching medical students and in making psychotherapy understandable to psychiatric trainees. Ian Kerr is Senior Registrar in Psychotherapy at and South West London and St George's Mental Health Trust and the Henderson Hospital. He is interested in the application of cognitive-analytic therapy (CAT) in community mental health teams and is researching CAT in the treatment of antenatal anxiety. 
1991), and a child's secure or insecure experience in infancy is highly predictive of the quality of later relationships with people other than the parents (Sroufe, 1983).

So in new situations we have expectations that are partly determined by our realistic perceptions, thoughts and feelings about the present, and partly by associated experiences we have had in the past (Hughes, 1999). Most people can usually evaluate the expectation against the reality of the present and adjust expectations accordingly. However, in some circumstances, such as when we are highly anxious, this appears to be more difficult, and we may cling defensively to our preconceptions. In addition, some people have habitual difficulty in adjusting their inner world to match their perceptions in the present. This is characteristic of some more rigid kinds of personality, including people with borderline personality features, where the person often has difficulty in distinguishing what is expected from the internal model and what is perceived in the external world (Kernberg, 1994).

\section{The place of projective mechanisms}

We tend to see what we expect to see (Abercrombie, 1989). Not only that, but we may behave towards other people as though they are the people we expect them to be. In the process, we give subtle non-explicit messages about what part they are playing, and the other people are covertly invited to adopt the role or behaviour that is expected (Sandler, 1976; Ryle, 1998). We project an existing mental model on to the present, and may then behave in a way that is appropriate for the internal model, but that may be

Box 1. The therapeutic alliance

There are three parts to the therapeutic relationship: the therapeutic alliance, the transference and the countertransference

The therapeutic alliance is the rational (implicit) contract between doctor and patient

The contract may be straightforward with mutual cooperation

The contract may be complicated by a covert agenda: the patient's unconscious and unspoken wishes and needs (the transference) inappropriate to the reality of the present external world.

\section{Unconscious expectations and transference}

Dr Breuer's alarming experience of being the object of Anna O's intense affection cannot have been the first and certainly was not the last time a patient fell in love with his or her doctor (Breuer \& Freud, 1895). The difference in Breuer's case was the use to which Sigmund Freud put the event. Rather than accepting it as one of those unfortunate things that happens to doctors, he thought about what it meant and persuaded a shaken and reluctant Breuer to collaborate with him on a theoretical paper and a book. Studies on Hysteria discusses the phenomenon in which a patient strays from strictly professional feelings towards the analyst, and allows personal feelings to intrude into the therapy. These patients had tended to "transfer on to the figure of the physician" distressing ideas that arose from the content of the analysis. These patients, said Freud, had made a "false connection" on to the analyst. Freud first actually used the term 'transference' in relation to his patient Dora, when he belatedly recognised the arousal of feelings towards himself that related to her lover - which led to Dora's abrupt withdrawal from treatment and a therapeutic failure (Freud, 1905).

\section{Transference}

\section{Definition}

Transference is the phenomenon whereby we unconsciously transfer feelings and attitudes from a person or situation in the past on to a person or situation in the present. The process is at least partly inappropriate to the present (see Box 2).

Points to note

(a) The process of transference is not conscious, and the patient unwittingly projects a needed aspect of a previously experienced or wishedfor relationship on to the doctor (see Box 3). Because it is a relationship that is 'transferred', the patient and doctor are expected to take complementary roles. So a patient who is afraid that he or she is seriously ill may adopt a helpless child-like role and project an omnipotent parent-like quality on to the doctor, who is then expected to provide a solution. 
Box 2. Transference

Transference is unconscious

It is at least partly inappropriate to the present

It is the transferring of a relationship, not a person

Only an aspect of a relationship, not the entire relationship, is transferred

(b) A relationship of the complexity of, say, a mother and son, is not likely to be fully reenacted. More likely is that some aspect of the relationship is played out in the transference - for example, a mother who sorts things out when her son is helpless, or a mother who criticises however hard he tries.

(c) The person projected in the transference relationship may not be historically accurate, but is the current mental representation of a previously experienced relationship. This is likely to be a mixture of the real historical relationship, the child's interpretation of this at the time, and perhaps some revision made since the original model was laid down.

(d) The transference projection may be considered a communication of a patient's needs that cannot be verbally expressed but that is instead enacted.

Transference is part of the way we relate to each other inside and outside psychotherapy, psychiatry and medicine, and we have to manage it as best we can. Much of the time, it is simply a part of the complexity of any relationship, and is not a problem for either party. For example, a junior member of staff may admire a senior colleague and unconsciously model his or her professional behaviour on his or her senior. Strictly speaking, this might be

\section{Box 3. Projection and transference}

Transference involves the projection of a mental representation of previous experience on to the present

Other people are treated as though they are playing the complementary role needed for the projected relationship

There are subtle (unconscious) behavioural 'nudges' to take on these feelings and behaviours considered to include an element of transference: the junior may need a parental figure to idealise. This may be helpful in the short term and in the long term is likely to resolve as he or she gains confidence and status. There is no reason to interpret the behaviour, and we generally regard this as a normal part of the process of training. On the other hand, if this particular admiration leads the junior to denigrate other seniors, or to adhere rigidly to one approach, it is unhealthy and the trainers would wish to discourage it.

Similarly, in a therapeutic relationship, the patient may show some mildly inappropriate feelings either positive or negative - which do not seriously interfere with treatment. Although these may be transference feelings, if they do not impair treatment, then there is no need to challenge them by interpretation, nor to change the treatment approach. At other times, the patient's inappropriate feelings and behaviours may dominate the relationship and impede the work to be done. To the extent that transference feelings represent an unconscious agenda for the patient, it is useful for staff to recognise it as far as possible so that an understanding of what the patient wants or expects can be used in planning clinical management. Describing this interpretation to the patient is not always useful (see below).

\section{Perception and misinterpretation}

Transference is promoted by unconscious expectations and what we perceive will be coloured by our expectations. Thus, distortions may take place in the patient's understanding of an interaction.

An in-patient has become very attached to the senior house officer (SHO) who has been seeing her weekly. She tells him that she feels very depressed because people do not like her when they get to know her. He says that perhaps she feels that way about him also and she agrees. He assures her that he really does like her. To his dismay he then hears from the nurses that she has told another patient that he 'fancies' her.

\section{What is not transference?}

Crying 'transference!' can become the defence of the doctor (or other health care worker) against a patient's justifiable feelings towards the team or a member of it. Not all feelings that a patient has towards his or her therapist are transference feelings. For example, a patient's hostility or anger may be an appropriate response to his or her situation. If the doctor or the team is regularly late, insensitive or inconsistent then the patient may 
reasonably be angry or disappointed. Or, if the patient is aware that a team member has put a lot of work into the treatment, he or she may be grateful and feel real warmth towards this keyworker. These appropriate feelings do not constitute transference.

Some patients are especially sensitive to failures in care, so there may be an element of transference coexisting with justifiable anger or disappointment. The most appropriate way to deal with this is for the doctor to acknowledge his or her lateness, inconsistency, etc., apologise, and, if relevant, explore why it is especially difficult for this patient.

Equally, a patient may have real and appropriate affection mixed with idealisation and a wish for an intimate relationship. Interpretation may not be appropriate, as it may humiliate the patient and damage the positive aspects of their working relationship. Instead, the therapist should recognise the patient's feelings and treat him or her with respect, continuing care but maintaining a strict attention to boundaries, so that the patient is not encouraged to feel that his or her affection is reciprocated or that his or her fantasies have a place in reality.

\section{Factors that increase transference}

Three things can promote transference: the situation of being in need and dependent on the doctor or team; the setting of a relationship where dependency needs are recognised and met; and particular types of personality where the internal world is compellingly projected on to the present (see Box 4).

\section{Situation}

Situations in which a person is relatively helpless or afraid will increase his or her need of a protective relationship. Since this applies to most patients in the care of a psychiatric team, we should expect there to be a transference element to most treatments. However, the term 'protective' does not do justice to the complexity of such a relationship. A person may

Box 4. Factors that increase transference

Vulnerable personality, especially people with borderline features, who may rigidly project their expectations on to the present

The patient's anxiety about his or her physical or psychological safety (e.g. when sick and afraid)

Frequent contact with a service or with a keyworker long for intimacy but also fear it, be intensely dependent but hate his or her dependency, become deeply attached but unable to trust the object of his or her attachment.

\section{Setting}

Any therapeutic setting where a person is seen frequently (and sometimes even infrequently) and his or her emotional needs attended to promotes transference. The patient may develop a transference relationship with a person, with a team or even with an institution. Frequent changes of keyworker are unlikely to avoid the development of transference feelings, but may displace them to the institution, which may be experienced as an unpredictable and frustrating other. A relationship where the patient feels recognised and understood improves cooperation; repeated changes of therapist are likely to impair it.

\section{Personality}

A person who has little capacity to reflect on his or her own state of mind, feelings and needs is vulnerable to acting upon feelings rather than reflecting or discussing what he or she wants.

If the patient has a vulnerable personality, is ill and afraid, and has the attention of a keyworker or team, he or she is therefore especially likely to develop transference feelings towards one or more people.

\section{Managing transference}

In dynamic psychotherapy, one of the aims of therapy is to 'resolve the transference', that is to help the patient recognise and manage the unconscious feelings and expectations which he or she brings to new relationships. The patient has to be able to move from a less reflective to a more reflective state of mind, where he or she can bring thought to bear on his or her feelings rather than enacting his or her expectations. Not all psychiatric patients will be able to do this: some will feel puzzled, misunderstood, humiliated or over-excited if their feelings and behaviours are interpreted in terms of underlying wishes and needs. Often, the psychiatrist and the team have to manage the transference relationship without explicit interpretation of the transference.

When the patient is unable to understand and use interpretation, then management should include recognition of his or her feelings towards the keyworker and team, with strategies intended to promote a secure and calming relationship. If the patient cannot always recognise the professional nature of the relationship, it is important that the 
therapist and team can hold on to it. The patient should feel 'held' without being over-stimulated, that is, he or she should feel that someone recognises his or her problems and feelings, and is concerned, and that the working relationship is reasonably stable and predictable (see Box 5).

\section{Recognition of the importance of the relationship}

It is essential that the doctor/keyworker recognises that this relationship is important to the patient (see Box 6). For the doctor, it may be a routine part of the week's work, and he or she must constantly be aware that the relationship is skew and that the patient's emotional needs almost inevitably go beyond the rational contract of the therapeutic alliance.

Mr A has long-standing personality problems and is admitted to a psychiatric ward after taking a lifethreatening overdose. He is seen weekly by Dr B, $\mathrm{SHO}$ on the ward, and rapidly comes to feel that she is someone he can trust. Dr B goes on holiday without warning him and he takes another overdose.

\section{Reliability}

Establishing a relationship with a dependent patient is a necessary part of treatment and the inevitable transference must be sensitively handled. If the doctor or keyworker is unreliable, this will not lessen the transference but will complicate it. Making and keeping appointments is professional and is calming for the patient. Unreliability increases anxiety and, apart from the discourtesy to the patient, is likely to intensify insecurity, increase patient hostility and undermine the therapeutic alliance and patient compliance.

A senior nurse was asked to take over a ward for patients with personality disorder where there had been a high rate of 'untoward incidents'. He was shocked to find that there was no forum for different

Box 5. Managing transference

Recognising the importance of the relationship to the patient

Reliability

Maintaining professional boundaries and clear limits in treatment

Interpretation, but only when the patient can understand and use it disciplines to meet, no agreed clinical management rules, and that 'psychotherapy' appointments were made on a casual basis and frequently changed at short notice. He established a strict system of rules for the ward and the untoward incident rate dropped substantially.

\section{Attention to boundaries}

The professional boundaries of the doctor-patient relationship provide the structure within which treatment can take place. This includes monitoring and setting limits on both the patient's and the doctor's behaviour. Some patients long for a personal relationship with the doctor or keyworker and there may be pressure to provide the responses of a friend rather than a professional.

Ms $C$ was an articulate and engaging patient who pleaded that her therapist show his care for her with a physical gesture, not just with words. The therapist was moved by her distress and several times held her when she was sobbing during a session. Ms C found these occasions deeply satisfying, and hoped that this would lead to a friendship. When therapy ended she felt hurt and humiliated that the therapist could leave her.

\section{Transference in reverse}

Q: What's the difference between God and a doctor?

A: God doesn't think he's a doctor.

If transference of expectations from previous relationships can happen in all relationships, we should expect it to affect doctors too. We all know doctors who apparently think they are God, and expect patients and junior staff to fulfil the

Box 6. Why recognise transference in general psychiatry?

Supports staff by helping them understand what is going on in the relationship with the patients, so reducing anxiety and overresponsibility

Improves patient management by recognising wishes that are not clearly articulated

Anticipates problem areas for patients and so more appropriate therapeutic provision

Helps avoid staff acting-out and improves boundary maintenance 
corresponding role. We also know doctors who are compulsive mothers, or who are afraid of patients demands, or who are excited by high-risk treatments. Aside from these extreme examples, we each have situations in our work that will trigger unthinking reaction at the expense of thoughtful response and management.

Naturally, we want to recognise our own preconceptions and foibles so that we do not impose them too much on relatively helpless patients (or even colleagues). Honest discussion with team members can be a help - so can the training experience of supervised psychotherapy, where our own assumptions can be reviewed. Some psychiatrists have personal therapy to explore attitudes and beliefs that are not entirely conscious.

\section{Countertransference}

\section{Definition}

Countertransference is the response that is elicited in the recipient (therapist) by the other's (patient's) unconscious transference communications (see Box 7). Countertransference response includes both feelings and associated thoughts. When transference feelings are not an important part of the therapeutic relationship, there can obviously be no countertransference.

The degree to which the projected role is congruent with some aspect of the personality of the recipient will affect the likelihood of his or her adopting it.

(a) A projected role may be very different from any aspect of his or her personality and the recipient is able to recognise that this perception of his or feelings or behaviour is a product of the patient's mind.

Mr D was a young man with a long history of unstable relationships, depressive episodes and alcohol misuse attending a day hospital. He was often hostile to his keyworker whom he accused of not caring whether he lived or died. The keyworker was an experienced community psychiatric nurse and was confident that she was neither negligent nor uncaring about her patient. She was aware that Mr D projected a scenario in which he was neglected and at risk, while she was experienced as a callous uncaring parent. Her recognition of this transference allowed her to remain calm and supportive and not to retaliate.

(b) A role may be congruent with an aspect of the therapist's personality and he or she may unconsciously accept and collude with the projection.
Box 7. Countertransference

Includes the feelings evoked in the doctor by the patient's transference projections

These can be a useful guide to the patient's expectations of relationships

They are easier to identify if they are not congruent with the doctor's personality and expectation of his or her role

Awareness of the transference-countertransference relationship allows reflection and thoughtful response rather than unthinking reaction from the doctor

Ms E had a long history of repeated treatment episodes for eating disorder, depression and relationship problems. Following a move to university, the university general practitioner referred her to the local psychiatric service for treatment. She confided in the young SHO that he was the first doctor to whom she had been able to talk freely, and that she had told him things she had never told previous doctors. The doctor enjoyed this idealisation and accepted that he had a special relationship with the patient. (See also 'Transference in reverse' above.)

\section{Patients who do not get better}

Patients who appear to have bypassed the rational therapeutic contract and who resist recovery over a long period of time despite getting good conventional treatment may be a particular source of frustration. Some frankly want a simple contact relationship with the doctor and have no interest in treatment or cure. If the doctor gets angry and rejecting, it is likely to increase the patient's anxiety and intensify his or her demands or cause them to go to a colleague. Most doctors or teams resolve this problem with limited but reliable non-interventionist contact.

Ms F was a 50-year-old woman who had many depressive episodes and somatic complaints throughout her life. She was a frequent attender at her general practitioner's (GP's) surgery. The GP found that a 15-minute monthly appointment kept her relatively well, and that her demands did not escalate.

Some patients have a more destructive agenda with a wish to engage the doctor in a therapeutic endeavour with the ultimate aim of proving that he or she, the patient, is untreatable. This interaction requires a helpful person who keeps trying. Such patients may leave a string of failed therapists in their wake. 
Mr G is a man of 30 who lives with his parents and despite high intelligence works in a low-paid clerical job. He has had many treatments for depression and "inability to sort [his] life out". Whatever is advised, and whatever interpretations made, he returns to the next session to explain why any change has been impossible. At the end of his most recent failed therapy, he says sympathetically, "I don't want you to feel bad doctor, I've defeated five therapists before you".

\section{Reaction and reflection}

Reaction might be called therapist acting-out. It happens when we either play the role unconsciously given to us by the patient or when we are aware of not being seen as we are and respond with anxiety or anger. Much of the time we have to tolerate not understanding what is going on without panicking. We should not be provoked into precipitate and premature action simply to reduce our own anxiety.

In the weekly ward round, the consultant sees that a patient with personality disorder has been an inpatient for six weeks. He feels that the patient is exploiting the service. He says angrily that the patient is getting dependent and must be discharged by the end of the week. (See also 'Transference in reverse' above.)

Reflection demands a reasonable level of awareness of one's own thoughts and feelings, and a sound grasp of whether these deviate from good professional behaviour. Good practice includes:

- a questioning attitude towards one's own feelings and motives

- recognition that we all have 'blind spots'

- an understanding that staff are affected by patients

- an understanding that patients are affected by staff behaviour

- a recognition that patients often have strong feelings towards staff.

\section{Dealing with countertransference}

Working with people who have psychotic or chaotic mental states can be stressful. Such patients have a powerful ability to project painful states of mind into the people who treat them. We may feel confused, despairing, angry or even murderous. This kind of stress can contribute to low morale and burnout, and it is important that we find ways to deal with it. Useful strategies include:

- reflection: see above

- using the team to clarify what a difficult patient projects into the treatment relationship - often, several members of the group can contribute to an understanding of the patient's transference to the team or to individuals (Kerr, 1999)

- using a specialist psychotherapist to help understand what the patient is unconsciously communicating in his or her behaviour

- undergoing personal therapy to become more aware of one's own unconscious needs and fears.

\section{Conclusion}

An understanding of transference and countertransference is essential to good practice in general psychiatry and may be helpful in general medical practice, especially general practice. Being aware of the hidden agenda in the clinical relationship will help the doctor recognise some of the patient's wishes and fears, which are not fully conscious and which can contribute to conflict or intense dependency. The doctor is then more likely to be able to stand back a little from the patient's emotional demands and avoid getting caught up in an agenda where he or she too reacts emotionally rather than thoughtfully. This is therapeutic both for the patient, whose clinical management will be informed by a greater understanding of his or her needs and motives, and for the doctor, who is less vulnerable to being exhausted by unrecognised and intrusive projections.

\section{References}

Abercrombie, M. L. J. (1989) The Anatomy of Judgement: An Investigation into the Processes of Perception and reasoning. London: Free Association Books.

Balint, M. (1957) The Doctor, His Patient and the Illness. London: Pitman.

Breuer, J. \& Freud, S. (1895) Studies on Hysteria. Reprinted (1953-1974) in the Standard Edition of the Complete Psychological Works of Sigmund Freud (trans. and ed. J. Strachey), vol. 2. London: Hogarth Press.

Fonagy, P., Steele, M. \& Steele, H. (1991) Maternal representations of attachment during pregnancy predict the organisation of mother-infant attachment at one year of age. Child Development, 62, 891-901

Freud, S. (1905) Fragment of an analysis of a case of hysteria. Reprinted (1953-1974) in the Standard Edition of the Complete Psychological Works of Sigmund Freud (trans. and ed. J. Strachey), vol. 7, pp. 3-122. London: Hogarth Press.

Greenson, R. R. (1985) The Technique and Practice of Psychoanalysis. London: Hogarth Press.

Hughes, P. (1999) Dynamic Psychotherapy Explained. Oxford: Radcliffe Medical Press.

Kernberg, O. (1994) Internal World and External Reality. Northvale, NJ: Jason Aronson.

Kerr, I. B. (1999) Cognitive analytic therapy for borderline personality disorder in the context of a Community Mental Health Team: individual and organisational psychodynamic implications. British Journal of Psychotherapy, 15, 425-438. 
Ryle, A. (1998) Transferences and countertransferences: the cognitive analytic perspective. British Journal of Psychotherapy, 14, 303-309.

Sandler, J. (1976) Countertransference and role-responsiveness International Review of Psychoanalysis, 3, 43-47.

Sroufe, L. A. (1983) Infant-caregiver attachment and patterns of adaptation in pre-school: The roots of maladaptation and competence. In Minnesota Symposium in Child Psychol ogy (ed. M. Perlmutter), pp. 41-81. Hillsdale, NJ: Erlbaum.

\section{Multiple choice questions}

1. Transference:

a is an unconscious process

$\mathrm{b}$ is always related to a previous parental relationship

c is usually inappropriate to the present

d is often part of relationships outside psychiatry.

2. Transference:

a is always damaging to the doctor-patient relationship

b should always be interpreted to the ptient

c is often intense in patients with borderline personality disorder

d can be avoided by frequent change of therapists.

3. Factors that are important in dealing helpfully with the transference relationship include:

a reliability of the doctor or keyworker

b attention to boundaries in the relationship

c recognising the importance of the relationship to the patient

d discharging the patient quickly to avoid dependency.
4. Recognising transference in the therapeutic relationship:

a increases the workload of the keyworker

b supports staff by helping them understand what is going on

c encourages dependency in difficult patients

$\mathrm{d}$ anticipates problem areas for patients.

5. Countertransference feelings:

a may be stressful for the doctor

b can be a useful tool in understanding the patient

c should be interpreted to the patient

d may be clarified by team discussion.

\begin{tabular}{|c|c|c|c|c|c|c|}
\hline 1 & 2 & 3 & & 4 & & 5 \\
\hline a $\mathrm{T}$ & a $F$ & & $\mathbf{T}$ & & F & a $\mathrm{T}$ \\
\hline F & b F & & $\mathbf{T}$ & b & $\mathrm{T}$ & b $T$ \\
\hline $\mathbf{T}$ & c $\mathbf{T}$ & & $\mathbf{T}$ & c & F & c $\mathrm{F}$ \\
\hline d $T$ & d F & & F & d & $\mathrm{T}$ & d $T$ \\
\hline
\end{tabular}

\section{Visit the Royal College of Psychiatrists web site at} httpr//www.rcpsych_ac.uk

\section{Information on:}

- press and public initiatives

- conferences

- college books and journals

- examinations

- postgraduate education

- the College Research Unit

\section{And for members:}

- information on divisions, faculties, sections, SIGS, committees and more

For further information, please e-mail: lalexander@rcpsych.ac.uk 